\title{
A systematic review of complications associated with nasal augmentation implants: expanded polytetrafluoroethylene (Gore-Tex) versus silicone
}

\author{
Han Le Thuc Hoang, MD' ${ }^{1}$, Michael Januszyk, MD² , J. Brian Boyd, MD² \\ ${ }^{1}$ Institute of Cosmetic and Reconstructive Surgery, Fountain Valley, CA, USA, ${ }^{2}$ Department of Surgery, University of California, Los Angeles, CA, USA
}

\begin{abstract}
Background: Augmentation rhinoplasty has been one of the most common cosmetic procedures in Asian population. Silicone is the most widely used nasal augmentation material in Asia. However, in the past few decades, expanded polytetrafluoroethylene (ePTFE, Gore-tex ${ }^{\circledast}$ ) has become more popular as an alternative.

Objective: In this study, complications associated with each implant aresystematically reviewed.

Methods: Heuristic searches of MEDLINE, PubMed, and the Cochrane Library were performed using the keywords "ePTFE", "Goretex", "silicone", and "rhinoplasty" to identify manuscripts for inclusion. The reference lists of these articles were systematically reviewed to further identify relevant articles. Only studies with detailed complication reports (i.e., infection, malposition) were considered. Random effects meta-analysis was performed to calculate the significance of differences in complication rates between silicone and ePTFE.

Results: Eighteen studies encompassing a total of 7,759 patients were analyzed, 12 with ePTFE and 6 with silicone. Among studies in which sex was reported, $88.8 \%$ of the patients were female. $88.4 \%$ of cases in the silicone group were primary, as compared to $78 \%$ in the ePTFE group. Overall complications were $5.3 \%$ for the ePTFE group and $9.2 \%$ for silicone $(p<0.05)$. Infection rate was similar between the two groups, $1.4 \%$ for ePTFE versus $1.9 \%$ for silicone group ( $p>0.05$ ). Exposure rate was also similar, $0.7 \%$ for silicone and $1.2 \%$ for ePTFE $(p>0.05)$. Malposition rates were significantly lower in ePTFE group compared to those receiving silicone implants $(2.4 \%$ versus $6.8 \%, p<0.05)$.

Conclusion: Although the gold standard graft material for rhinoplasty remains autologous tissue, implant based rhinoplasty is far more common in Asian populations. Both silicone and ePTFE have acceptable risk profiles when used in selective patients for dorsal augmentation. However, given the additional risks of capsular contracture and implant malposition associated with silicone implants, ePTFE should be considered as a first-line option for implant-based nasal augmentation.
\end{abstract}

Keywords: ePTFE; Gore-tex; nasal augmentation; rhinoplasty; silicone

\section{Introduction}

The common nasal aesthetic complaints from Asian patients are: lack of dorsal height, short nose, round and ill-defined tip, and wide and thick ala. To address these complaints, an aug- mentation rhinoplasty including increased tip projection and ala reduction is often required. The augmentation rhinoplasty procedure has long been one of the most common cosmetic procedures in Asian populations [1-3], and silicone is the most widely used nasal augmentation material in Asia [2-5]. How-

Received February 5, 2018; Revised June 12, 2018; Accepted June 14, 2018

Corresponding author: Han Le Thuc Hoang

E-mail: hanhoang@gmail.com, ORCID: https://orcid.org/0000-0001-9011-1254

This is an Open Access article distributed under the terms of the Creative Commons Attribution Non-Commercial License (http://creativecommons.org/licenses/by-nc/4.0), which permits unrestricted non-commercial use, distribution, and reproduction in any medium, provided the original work is properly cited.

Copyright (c) 2018 Korean Society of Korean Cosmetic Surgery and Medicine (KSKCS \& KCCS). 
ever, in the past few decades, expanded polytetrafluoroethylene expanded polytetrafluoroethylene (ePTFE, Gore-Tex ${ }^{\circledR}$ ) has become more popular as an alternative implant [2-5]. Both implant materials have been used for decades in plastic and cardio-vascular surgery, and they both have excellent biocompatibility profiles. The solid silicone implants used for nasal augmentation are known to induce a tissue reaction, resulting in capsular contracture $[6,7]$, as seen in other types of silicone implants. This is in addition to the standard implant-related complications. The ePTFE, which has been used in surgery for as long as silicone has been employed, has been thought to have a higher infection rate due to the porous nature of the implant. This concern, along with the technical difficulty in removing the implant, has swayed many surgeons to avoid using ePTFE implants [1-3]. In this study, complications associated with each implant are systematically reviewed.

\section{Materials and methods}

\section{Search strategy}

Two independent reviewers performed heuristic searches of MEDLINE, PubMed, and the Cochrane Library using the keywords: "ePTFE", “Gore-Tex", "silicone”, and "rhinoplasty", to identify manuscripts for inclusion. The reference lists of these articles were systematically reviewed to further identify relevant articles.

A total of 267 articles were found on PubMed using "silicone" and "rhinoplasty", 108 using "Gore-Tex" and "rhinoplasty", and 16 using "ePTFE" and "rhinoplasty". MEDLINE yielded the same articles. Only studies with detailed complication reports (i.e., infection and malposition) were considered.

\section{Data extraction}

Two reviewers reviewed the articles and extracted data independently. Any discrepancies were resolved through an independent review by the senior author. Collected data included: the number of subjects; gender; age and age range; number of revision rhinoplasty patients within the studied population; history of nasal trauma; follow-up; overall complications; as well as implant-related complications such as: infection, malposition, exposure, the need for reoperation, and the need for implant removal.

The paired sample t-test was performed to calculate the significance of differences in complication rates between the silicone and ePTFE groups.

\section{Results}

Eighteen studies. encompassing a total of 7,759 patients were analyzed; 12 with ePTFE and 6 with silicone implants (Table

Table 1. Demographics of patients in included studies demographic

\begin{tabular}{|c|c|c|c|c|c|}
\hline Reference & Implant used & Patient (n) & Female (n) & Age (yr) & Revision \\
\hline Deva et al., $1998[8]$ & Silicone & 422 & 413 & $26(17-36)$ & 41 \\
\hline Zeng et al., 2002 [9] & Silicone & 98 & 77 & NR (17-49) & NR \\
\hline Lam and Kim, 2003 [10] & Silicone & 1,079 & NR & NR & NR \\
\hline Ahn et al., 2004 [11] & Silicone & 100 & 93 & NR & 28 \\
\hline Tham et al., 2005 [12] & Silicone & 355 & 316 & $26(13-67)$ & 52 \\
\hline Chuangsuwanich and Lohsiriwat, 2013 [13] & Silicone & 548 & 519 & NR & 45 \\
\hline Godin et al., 1999 [14] & ePTFE & 309 & NR & NR & 147 \\
\hline Lohuis et al., 2001 [15] & ePTFE & 66 & 44 & NR & 47 \\
\hline Jin et al., 2006 [16] & ePTFE & 853 & NR & NR & 197 \\
\hline Inanli et al., 2007 [17] & ePTFE & 74 & 45 & $30(22-48)$ & 28 \\
\hline Conrad et al., 2008 [18] & ePTFE & 521 & 399 & $13-70$ & NR \\
\hline Dong et al., 2010 [19] & ePTFE & 1,700 & 1,570 & $18-57$ & 0 \\
\hline Hong et al., 2010 [20] & ePTFE & 257 & NR & $24(18-57)$ & 476 \\
\hline Yap et al., 2011 [21] & ePTFE & 1,054 & 955 & $34(15-72)$ & 46 \\
\hline Serin et al., 2012 [22] & ePTFE & 32 & 20 & 28.4 & 23 \\
\hline Winkler et al., 2012 [23] & ePTFE & 75 & NR & $46(7-86)$ & NR \\
\hline Shadfar et al., 2015 [24] & ePTFE & 40 & 24 & 36.8 & NR \\
\hline Joo and Jang, 2016 [25] & ePTFE & 176 & 80 & $30.3(11-69)$ & 41 \\
\hline
\end{tabular}

Values are presented as number or mean (range).

NR, not reported; ePTFE, expanded polytetrafluoroethylene. 
1 [8-25]). Of the studies in the silicone group, 3/6 reported age ranges and/or average age, and 9/12 studies in the ePTFE group reported these variables. Of the 6 studies in the silicone group, 5 reported gender, with $93.2 \%$ female patients. Of the 12 ePTFE studies, 8 reported gender, with $87.4 \%$ female patients. The differences in gender were not significant between the 2 groups ( $p>0.05$ ). Of the studies in the ePTFE group, 9/12 reported revision sub-groups, as compared to $4 / 6$ studies in the silicone group. Out of the studies that reported revision cases, $88.4 \%$ of cases in the silicone group were primary, as compared to $78 \%$ in the ePTFE group (Table 1).

Of the 12 studies in the ePTFE group, 9 reported the mean follow-up (range, 11.4 to 71 months), of which 8 also reported the follow-up range (range, 0 to 17 years). The reported followups were much lower in the silicone group. Only 2 studies out of 6 reported any follow-up. Ahn et al. [11] reported a 2 to 5-year follow-up. Tham et al. [12] reported a mean follow-up of 160 days, with a range of 3 months to 3 years (Table 2).

Overall complications were $5.3 \%$ for the ePTFE group and $9.2 \%$ for the silicone group. This difference was statistically significant $(\mathrm{p}<0.05)$. The infection rate was similar between the 2 groups; $1.4 \%$ for ePTFE versus $1.9 \%$ for the silicone group ( $p>0.05$ ). The exposure rate difference was not statistically significant between the 2 groups; $0.7 \%$ for silicone and $1.2 \%$ for the ePTFE group ( $p>0.05)$. However, malposition rates were significantly lower in the ePTFE group when compared to those receiving silicone implants (2.4\% versus $6.8 \%$, $\mathrm{p}<0.05$; Table 3 ).

\section{Discussion}

Rhinoplasty is one of the most common cosmetic surgeries requested and performed worldwide [26]. Yet, the revision rate is notoriously high when compared to other cosmetic procedures, and it is reported to be $5 \%$ to $15 \%$ [27]. One may argue that a rhinoplasty specialist may have a lower rate; however, it is difficult to truly assess, as patients often change surgeons or even go to different cities and different countries to have cosmetic surgeries performed. In Asian rhinoplasty, augmentation is a key part of the surgery, and implants are used almost exclusively in Asia, particularly for primaries [1-5]. Both silicone and

Table 3. Systemic analysis of silicone versus ePTFE groups

\begin{tabular}{lrrr}
\hline \multicolumn{1}{c}{ Variable } & Silicone & ePTFE & p-value \\
\hline Total no. of patient & 2,602 & 5,157 & \\
All complication & $239(9.2)$ & $271(5.3)$ & 0.017 \\
Infection & $50(1.9)$ & $71(1.4)$ & 0.426 \\
Malposition & $177(6.8)$ & $126(2.4)$ & 0.016 \\
Exposure & $18(0.7)$ & $56(1.1)$ & 0.039 \\
\hline
\end{tabular}

Values are presented as number only or $\mathrm{n}(\%)$. ePTFE, expanded polytetrafluoroethylene.

Table 2. Reported follow up, complications, infections, malpositions, and exposure, in included studies

\begin{tabular}{|c|c|c|c|c|c|c|c|}
\hline Reference & Implant used & $\mathbf{N}$ & Follow up & Complications & Infection & Malposition & Exposure \\
\hline Deva et al., 1998 [8] & Silicone & 422 & NR & 41 & 0 & 39 & 2 \\
\hline Zeng et al., 2002 [9] & Silicone & 98 & NR & 39 & 1 & 38 & 2 \\
\hline Lam and Kim, 2003 [10] & Silicone & 1,079 & NR & 60 & 28 & 40 & 0 \\
\hline Ahn et al., 2004 [11] & Silicone & 100 & $2-5 \mathrm{yr}$ & 6 & 0 & 5 & 0 \\
\hline Tham et al., 2005 [12] & Silicone & 355 & $3 \mathrm{mo}-3 \mathrm{yr}$ & 57 & 19 & 28 & 10 \\
\hline $\begin{array}{l}\text { Chuangsuwanich and } \\
\text { Lohsiriwat, } 2013 \text { [13] }\end{array}$ & Silicone & 548 & $\mathrm{NR}$ & 36 & 2 & 27 & 4 \\
\hline Godin et al., 1999 [14] & ePTFE & 309 & $5 \mathrm{mo}-10 \mathrm{yr}$ & 10 & 10 & 2 & 0 \\
\hline Lohuis et al., 2001 [15] & ePTFE & 66 & $3-72 \mathrm{mo}$ & 1 & 0 & 1 & 0 \\
\hline Jin et al., 2006 [16] & ePTFE & 853 & $\mathrm{NR}$ & 34 & 18 & 16 & 0 \\
\hline Inanli et al., 2007 [17] & ePTFE & 74 & $5-62 \mathrm{mo}$ & 1 & 0 & 1 & 0 \\
\hline Conrad et al., 2008 [18] & ePTFE & 521 & $1-17 \mathrm{yr}$ & 33 & 7 & 20 & 2 \\
\hline Dong et al., 2010 [19] & ePTFE & 1,700 & $6 \mathrm{~d}-4 \mathrm{yr}$ & 119 & 17 & 51 & 51 \\
\hline Hong et al., 2010 [20] & ePTFE & 257 & $12-98 \mathrm{mo}$ & 34 & 9 & 16 & 0 \\
\hline Yap et al., 2011 [21] & ePTFE & 1,054 & $\mathrm{NR}$ & 24 & 4 & 15 & 0 \\
\hline Serin et al., 2012 [22] & ePTFE & 32 & $6-34 \mathrm{mo}$ & 0 & 0 & 0 & 0 \\
\hline Winkler et al., 2012 [23] & ePTFE & 75 & $0-74 \mathrm{mo}$ & 6 & 4 & 0 & 2 \\
\hline Shadfar et al., 2015 [24] & ePTFE & 40 & NR & 2 & 1 & 1 & 1 \\
\hline Joo and Jang, 2016 [25] & ePTFE & 176 & 4-115 mo & 7 & 1 & 3 & 0 \\
\hline
\end{tabular}

Values are presented as number.

ePTFE, expanded polytetrafluoroethylene; NR, not reported. 
ePTFE implants have a long track-record with regards to biocompatibility and implant-related risks. This systematic review demonstrates that although the infection rate is comparable between the 2 types of implants, silicone has a statistically significant higher malposition rate and overall complication rate when compared to ePTFE. Other known complications associated with both types of nasal implants are capsular contracture and calcinosis. Kim et al. [6] recently published an extensive report on silicone capsular contracture in the nose. In their study, $29.3 \%$ of patients developed noticeable contracture, and $13.8 \%$ required capsulectomy plus or minus significant revisions. Chang and Jung [28] also reported a high rate of capsular contracture with silicone nasal implants in a new study published by the Journal of Cosmetic Medicine. In this study, $77 \%$ of all capsular contracture cases were related to the usage of silicone implants. Calcinosis of both type of implants has also been reported, however the data are very limited [29,30]. This study did not compare these complications due to their rarity and low reporting rate.

The most feared complication for any type of nasal implant is exposure. Looking in depth into the reviewed studies, this complication, in either the silicone or ePTFE groups, appeared to be almost exclusively related to implant placement within the tip. In the ePTFE group, Dong et al. [19] reported the highest exposure rate of $3 \%$. In their study, ePTFE was also used for tip augmentation. In the silicone group, Tham et al. [12] also reported a similar used and exposure rate. Given the above findings, the authors' recommendation is to use ePTFE implants for dorsal augmentation only.

There are several weaknesses to this systematic review. The included studies are heterogeneous. There was no control or randomization, and most of the studies are retrospective. Not all complications associated with nasal implants are included. However, this study captured many patients in both arms, and it had sufficient power to demonstrate statistical differences in the overall complication and malposition rates of each type of implant.

Although the gold standard graft material for rhinoplasty remains autologous tissue, implant-based rhinoplasty is far more common in Asian populations. Both silicone and ePTFE have been shown to exhibit acceptable risk profiles when used in selective patients for dorsal augmentation. However, given the additional risk of capsular contracture and implant malposition associated with silicone implants, as suggested by the findings of this systemic analysis, ePTFE should be strongly considered as a first-line option for implant-based nasal augmentation.

\section{Acknowledgments}

This research article was inspired by Dr. Han Hoang KCCS fellowship, and in particular, the teaching of doctor Chang Geun-Uck. KCCS is truly a leader and innovator in cosmetic surgery.

\section{Conflicts of interest}

The authors have nothing to disclose.

\section{References}

1. Jang YJ, Yi JS. Perspectives in Asian rhinoplasty. Facial Plast Surg 2014;30:123-30.

2. Li D, An Y, Yang X. An overview of Asian rhinoplasty. Ann Plast Surg 2016;Supp 1:S22-4.

3. Jin HR, Won TB. Rhinoplasty in the Asian patient. Clin Plast Surg 2016;43:265-79.

4. Sajjadian A, Naghshineh N, Rubinstein R. Current status of grafts and implants in rhinoplasty: Part II. Homologous grafts and allogenic implants. Plast Reconstr Surg 2010;125:99-109e.

5. Malone M, Pearlman S. Dorsal augmentation in rhinoplasty: a survey and review. Facial Plast Surg 2015;31:289-94.

6. Kim YK, Shin S, Kang NH, Kim JH. Contracted nose after silicone implantation: a new classification system and treatment algorithm. Arch Plast Surg 2017;44:59-64.

7. Sunwoo W, Jung H, Kim DW, Jin HR. Immunohistochemical analysis of capsular contracture in silicone implant rhinoplasty. JAMA Facial Plast Surg 2017;19:436-7.

8. Deva AK, Merten S, Chang L. Silicone in nasal augmentation rhinoplasty: a decade of clinical experience. Plast Reconstr Surg 1998;102:1230-7.

9. Zeng Y, Wu W, Yu H, Yang J, Chen G. Silicone implants in augmentation rhinoplasty. Aesthetic Plast Surg 2002;26:85-8.

10. Lam SM, Kim YK. Augmentation rhinoplasty of the Asian nose with the "bird" silicone implant. Ann Plast Surg 2003;51: 249-56.

11. Ahn J, Honrado C, Horn C. Combined silicone and cartilage implants: augmentation rhinoplasty in Asian patients. Arch Facial Plast Surg 2004;6:120-3.

12. Tham C, Lai YL, Weng CJ, Chen YR. Silicone augmentation rhinoplasty in an oriental population. Ann Plast Surg 2005; 54:1-5; discussion 6-7.

13. Chuangsuwanich A, Lohsiriwat V. Augmentation rhinoplasty with custom-made S-shape silicone implant in Asians: a 15- 
year experience. Indian J Plast Surg 2013;46:533-7.

14. Godin MS, Waldman SR, Johnson CM Jr. Nasal augmentation using Gore-Tex. A 10-year experience. Arch Facial Plast Surg 1999;1:118-21; discussion 122.

15. Lohuis PJ, Watts SJ, Vuyk HD. Augmentation of the nasal dorsum using Gore-Tex: intermediate results of a retrospective analysis of experience in 66 patients. Clin Otolaryngol Allied Sci 2001;26:214-7.

16. Jin HR, Lee JY, Yeon JY, Rhee CS. A multicenter evaluation of the safety of Gore-Tex as an implant in Asian rhinoplasty. Am J Rhinol 2006;20:615-9.

17. Inanli S, Sari M, Baylancicek S. The use of expanded polytetrafluoroethylene (Gore-Tex) in rhinoplasty. Aesthetic Plast Surg 2007;31:345-8.

18. Conrad K, Torgerson CS, Gillman GS. Applications of GoreTex implants in rhinoplasty reexamined after 17 years. Arch Facial Plast Surg 2008;10:224-31.

19. Dong L, Hongyu X, Gao Z. Augmentation rhinoplasty with expanded polytetrafluoroethylene and prevention of complications. Arch Facial Plast Surg 2010;12:246-51.

20. Hong JP, Yoon JY, Choi JW. Are polytetrafluoroethylene (GoreTex) implants an alternative material for nasal dorsal augmentation in Asians? J Craniofac Surg 2010;21:1750-4.

21. Yap EC, Abubakar SS, Olveda MB. Expanded polytetrafluoroethylene as dorsal augmentation material in rhinoplasty on Southeast Asian noses: three-year experience. Arch Facial Plast Surg 2011;13:234-8.

22. Serin GM, Polat S, Aksoy E, Baylançiçek S, Inanli S. Importance of placing Gore-Tex in the subperiosteal plane for aug- mentation rhinoplasty. J Craniofac Surg 2012;23:e359-61.

23. Winkler AA, Soler ZM, Leong PL, Murphy A, Wang TD, Cook TA. Complications associated with alloplastic implants in rhinoplasty. Arch Facial Plast Surg 2012;14:437-41.

24. Shadfar S, Farag A, Jarchow AM, Shockley WW. Safety and efficacy of expanded polytetrafluoroethylene implants in the surgical management of traumatic nasal deformity. JAMA Otolaryngol Head Neck Surg 2015;141:710-5.

25. Joo YH, Jang YJ. Comparison of the surgical outcomes of dorsal augmentation using expanded polytetrafluoroethylene or autologous costal cartilage. JAMA Facial Plast Surg 2016;18:327-32.

26. ISAPS. The International Study on Aesthetic/Cosmetic Procedures Performed in 2016 [Internet]. Hanover: International Society of Aesthetic Plastic Surgery, 2016 [cited 2017 Dec 28]. Available from: https://www.isaps.org/wp-content/uploads/2017/10/GlobalStatistics2016-1.pdf.

27. Neaman KC, Boettcher AK, Do VH, Mulder C, Baca M, Renucci JD, et al. Cosmetic rhinoplasty: revision rates revisited. Aesthet Surg J 2013;33:31-7.

28. Chang GU, Jung DH. A new classification system of nasal contractures. J Cosmet Med 2017;1:106-11.

29. Jang TY, Choi JY, Jung DH, Park HJ, Lim SC. Histologic study of Gore-Tex removed after rhinoplasty. Laryngoscope 2009; 119:620-7.

30. Jung DH, Kim BR, Choi JY, Rho YS, Park HJ, Han WW. Gross and pathologic analysis of long-term silicone implants inserted into the human body for augmentation rhinoplasty: 221 revision cases. Plast Reconstr Surg 2007;120:1997-2003. 